\title{
STIHIJSKI (NE)RAZVOJ NEURBANIZIRANEGA DELA MESTA NA PRIMERU LJUBLJANE
}

\author{
Aleš Smrekar \\ Geografski inštitut Antona Melika ZRC SAZU, Gosposka ulica I3, \\ SI - 1000 Ljubljana, Slovenija \\ e-mail: ales.smrekar@zrc-sazu.si
}

Izvirni znanstveni članek

COBISS 1.01

\section{Izvleček}

Urbanizacija povzroča spremembe $v$ mestih in tudi okoliški pokrajini ter bistveno odstopa od konceptov trajnostnega razvoja. Poglavitni vzrok današnjega stanja je odsotnost zrelega odnosa do življenjskega okolja. Na ožjih vodovarstvenih območjih na Ljubljanskem polju je prostor brez vsebine - če odmislimo črpanje vode -, ki omogoča divje vrtičkarstvo, nekontrolirano odvzemanje vode in gramoza ter odlaganje odpadkov. Mestna politika je naredila prve korake k sanaciji degradirane pokrajine.

Ključne besede: mesto, vrtiček, zasebni vodnjak, divje odlagališče odpadkov, gramoznica, ozaveščenost, Ljubljana, Ljubljansko polje.

\section{COINCIDENTAL (NON)-DEVELOPMENT OF THE NON- URBANIZED PART OF THE CITY IN THE CASE OF LJUBLJANA}

\begin{abstract}
Urbanization causes changes within cities and their surrounding areas and deviates from the concepts of sustainable development. The main cause of current condition is the lack of an adequate relation towards the environment. In narrow water-protection zones in the area of Ljubljansko Polje there are areas without any contents, if we don't take into account water pumping, which enables allotment gardening, uncontrolled taking of water and gravel and waste dumping. The municipality has made first steps towards the rehabilitation of the degraded landscape.
\end{abstract}

Key words: city, allotment garden, private well, illegal waste dump, gravel pit, awareness, Ljubljana, Ljubljansko Polje. 


\section{UVOD}

V preteklosti so pretežno naravni procesi povzročali spremembe obstoječe pokrajine, kot na primer potresi, poplave, požari... Rezultati teh procesov so bili odvisni od intenzivnosti in njihovega trajanja. Spremembe so lahko bile sčasoma popolnoma odstranjene, kar je pomenilo vrnitev v prvotno stanje. $\mathrm{V}$ primeru radikalnih in trajnih vplivov pa so se stari pokrajinski sistemi spreminjali $\mathrm{v}$ nove $\mathrm{z}$ ustreznimi in uravnoteženimi elementi (Richling 1999).

Podobno se je dogajalo s procesi, ki jih je sprožil človek. Med njimi ima proces urbanizacije prav posebno mesto, saj povzroča znatne spremembe v naravnem okolju in načine, kako ta deluje. Sprememb pa ne zaznavamo le v samih mestih, temveč tudi v okoliški pokrajini (Smrekar 2004).

V srednjeevropskem prostoru je razvoj mest skozi vso zgodovino tesno povezan s prodnimi ravnicami, saj je večina mest nastala prav ob velikih rekah ali njihovih pritokih, ki so te ravnine ustvarili (Galluser in Schenker 1992). Naravne sile, ki so do intenzivnejše poselitve edine oblikovale ta območja, so dobile tekmeca v človeku, ki je ponekod bolj in drugje manj intenzivno posegel v naravni tok dogodkov.

Preučevanje prodnih ravnin zahteva zaradi prepletanja medsebojno izključujočih se dejavnosti, zaradi degradiranosti in funkcijske vpetosti v mestni prostor holistični in interdisciplinarni pristop. Le tako se lahko v prizadetem okolju soočimo z naravnimi, pokrajinskoekološkimi, gospodarskimi, kulturnimi in socialnimi izzivi. Sodobna mesta gospodarsko razvitih držav, pri tem Ljubljana ni izjema, bistveno odstopajo od konceptov trajnostnega razvoja, saj njihove dejavnosti in mestno prebivalstvo za zadovoljevanje snovnih in energijskih potreb ter za odlaganje različnih emisij in odpadkov potrebujejo zelo obsežna zemljišča. Pri tem se neizbežno soočajo z omejitvami ekosistemov. Sposobnost ekosistema namreč omejuje tridimenzionalno pojmovan prostor, ki vključuje zaloge naravnih virov (neobnovljivih, pogojno obnovljivih in obnovljivih) in zmogljivost absorpcije odpadkov, onesnaževanja ter posegov v okolje(Plut 2003). Degradacija urbane pokrajine je torej posledica nesklenjenosti snovnih krogov (na primer odpadkov) in čezmerne rabe neobnovljivih energetskih virov (na primer gramoza), kar povzroča pokrajinske obremenitve in spremembe v pokrajinski sestavi ter dinamiki mesta in njegove okolice (Breg, Urbanc 2005).

V celotni Evropi se spopadajo s podobnimi problemi, zato je bila v letu 2007 sprejeta Leipziška listina o trajnostnih evropskih mestih. Podaja smernice za celostno politiko razvoja urbanih območij, ki vključuje ekonomsko, socialno in okoljsko dimenzijo, kar predstavlja temelj nacionalne urbane politike in ponuja strategije za izboljšanje degradiranih območij. V povezavi z Leipziško listino morajo države članice Evropske unije leta 2009 predložiti poročila o vplivih urbanega okolja na zdravje ljudi in okolje (Podobnik 2007). Torej naj bi ta listina predstavljala dobro podlago za nadaljnje aktivnosti za izboljšanje fizičnega okolja $\mathrm{V}$ urbanih območjih.

Splet (ne)ugodnih naravnih in družbenih potez je povzročil, da je del Ljubljanskega polja, ki bi moral biti zaradi svoje funkcije črpanja vode, strogo zaščiten, postal degradirana pokrajina. Poglavitni vzrok današnjega stanja je odsotnost zrelega odnosa do življenjskega 
Slika 1: Raba tal in vodovarstvena območja na Ljubljanskem polju.

Figure 1: Land usage and water-protection areas in the area of Ljubljansko Polje.

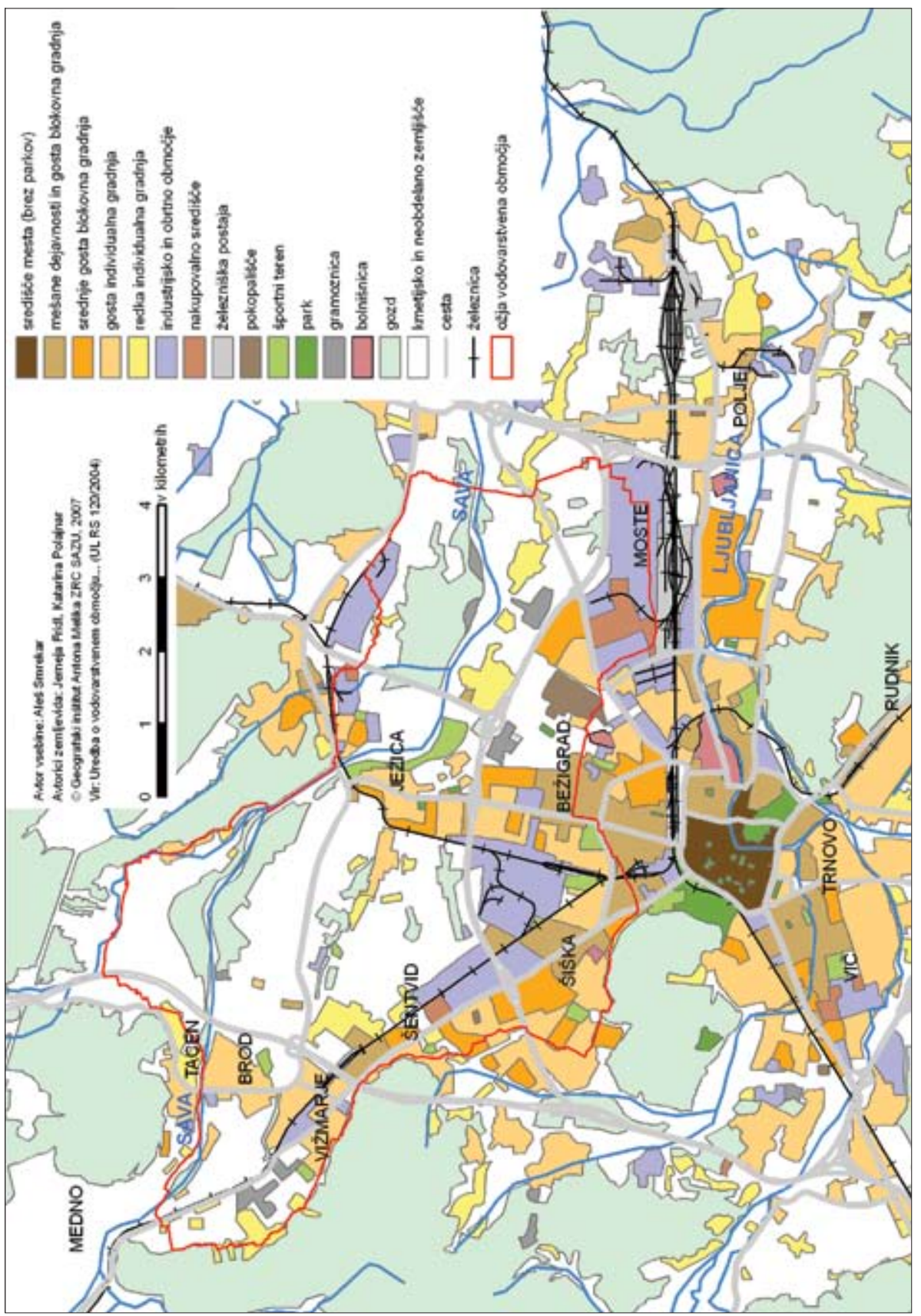


okolja. Gospodarsko ekstenzivna pokrajina žal ni našla pravega mesta v vrednostnem sistemu prebivalcev Ljubljane in njene okolice. Ekonomsko izkoriščanje, ki je slonelo na egocentričnem odnosu do okolja, je pripeljalo do tega, da je ta pokrajina postala manjvreden prostor. Spremembe v pokrajini, ki so se zgodile v zadnjega pol stoletja, so bolj kot posledica uradnih ukrepov posledica miselnosti v družbi (Urbanc in Breg 2005).

Ljubljana se je $\mathrm{v}$ zadnjih desetletjih razširila tudi na nekdanja kmetijska zemljišča. V neposredni bližini vodarn je marsikje to območje prostor brez vsebine - če odmislimo črpanje vode -, ki omogoča divje vrtičkarstvo, odvzemanje vode in gramoza ter odlaganje odpadkov. Območje je dobro dostopno, prepredeno s potmi, nedovoljene in nezaželene dejavnosti pa pospešuje neurejeno lastništvo. Poglavitni razlog okoljsko neugodnih razmer je brez dvoma pomanjkanje zrelega odnosa do življenjskega okolja (Smrekar 2006).

Območje, ki je v preteklosti omogočalo okolju prijazne dejavnosti, bi lahko zelo kmalu postalo okoljsko breme (Rejec Brancelj 2001). Zaenkrat analize vode še kažejo na njeno ustreznost, vendar je območje zaradi nenadzorovanih posegov že v preteklosti, ki se še vedno dogajajo, tudi prikrita grožnja, saj ne vemo natančno, kje in kakšna vse so stara bremena. Za celostno in dolgoročno uspešno rešitev problema zgolj sanacija prostora ne bo zadoščala, ampak bo potrebno ponovno vzpostaviti kulturne in socialne vrednote območja ter ga umestiti $v$ trajen vrednostni sistem meščanov.

\section{STIHIJSKI RAZVOJ NEDOVOLJENIH DEJAVNOSTI}

Neurbanizirana območja, ki so ostala neizkoriščena po gradnji in so dolgoročno predvidena za gradnjo ter posamezna kmetijska območja, na katerih je upadel interes za kmetijstvo, v posameznih primerih pa tudi za rekreacijska območja, ki čakajo na konkretnejše ureditvene posege za javno rekreacijsko ponudbo, so pod velikim pritiskom določenih skupin ljudi.

Ti marsikdaj vidijo ta prostor, ki je v veliki meri na vodovarstvenih območjih, za izvajanje neprimernih dejavnosti, kot so na primer vrtičkarstvo, individualno nedovoljeno odvzemanje vode iz podtalnice, odvažanje gramoza in nedovoljeno odlaganje odpadkov.

\section{I Vrtičkarstvo}

Vrtičkarstvo je ljubiteljsko vrtnarstvo, v razvitem delu sveta razširjeno zlasti na obrobjih večjih mest na za to posebej odrejenih in urejenih območjih. Tako naj bi bilo tudi pri nas, praksa v Ljubljani pa kaže, da gre pravzaprav za enega najbolj stihijskih porabnikov dragocenega mestnega prostora.

Glavni problemi, ki jih vrtičkarstvo v Ljubljani poraja so (Simoneti in drugi 1997):

- velika prostorska razširjenost;

- nepredvidljiva dinamika prostorske širitve;

- nenačrtovana, nenadzirana in pogosto povsem neformalna prostorska raba;

- zasedanje zemljišč, ki so okoljevarstveno problematična (ožji vodovarstveni pasovi, tudi neposredna bližina prvega, pasovi ob cestah, železnicah, vodotokih, onesnažena zemljišča, bližina visokonapetostnih daljnovodov); 
- $\quad$ izrivanje drugih prostorskih rab z mestnega območja;

- neurejen videz;

- $\quad$ postavljanje raznovrstnih objektov na vrtičkih in njihovo koriščenje za začasno bivanje;

- komunalna neurejenost (brez odvoza smeri, sanitarij ter vode za pitje in zalivanje); kopičenje odpadnega materiala;

- nekontroliran dostop avtomobilov;

- negativni vplivi na okolje zaradi nestrokovne pridelave.

Načeloma velja, da se je vrtičkarstvo izognilo mestnemu središču, v vseh drugih predelih pa se umešča na zelo različne lokacije. Pojavlja se ob ograjah poslovnih območij, na nasipih železniških prog, obrežjih vodotokov, ostankih neizkoriščenih gradbenih parcel, med njivami in travniki, na robu gozda in pred stanovanjskimi bloki.

Najbolj prostrana območja vrtičkov so bila do nedavnega na območjih Žal, vzhodno od Vojkove ceste in industrijske cone Šiška, na desnem bregu Save pri Črnučah. Sporadično so območja vrtičkov raztresena povsod, razen v strogem središču mesta ter na območjih Hrušice in Bizovika, kjer se predvideva strog režim varovanja večjih kompleksov kmetijskih zemljišč (Kladnik 2002).

Iz leta v leto narašča število majhnih, izsiljenih lokacij, za katere je očitno, da so odraz velike potrebe uporabnikov po obdelavi vrta in hkrati kažejo na odsotnost kakršnega koli nadzora lastnika ali upravljalca prostora nad njegovo rabo oziroma videzom. Le posamezna območja, ki so bila načrtno namenjena vrtičkarstvu, so primerno urejena in že dolgo v vrtičkarski rabi. Taka je na primer lokacija ob Litostroju, ki se je razvila sočasno s postavitvijo tamkajšnje stanovanjske soseske.

Ni dvoma, da je med obdelovalci vrtičkov mogoče razlikovati med dvema skrajnima skupinama, tisto, ki zaradi neznanja z uporabo gnojil in sredstev za varstvo rastlin močno pretirava, in ono, ki zaradi okoljske ozaveščenosti prisegajo na metode biološke pridelave. Vmes je še množica tistih, ki se nagibajo k eni ali drugi skrajnosti oziroma so v mejah povprečja. Kljub temu so zaradi velike intenzivnosti pridelave še vedno omembe vreden porabnik vode (za zalivanje), onesnaževalec podtalnice oziroma tekočih voda in zaradi neustreznega ravnanja $z$ odpadki tudi obremenjevalec divjih odlagališč odpadkov.

Nestrokovna uporaba fitofarmacevtskih sredstev in gnojil predstavlja nevarnost za vodne vire in za varno javno oskrbo s pitno vodo ter je pogosto $\mathrm{v}$ konfliktu $\mathrm{z}$ organizirano rabo prostora in urbanistično zasnovo mesta. V Ljubljani lahko pride zaradi nezadostnega nadzora in nezadostne okoljske ozaveščenosti vrtičkarjev v prihodnosti do nevarnih in škodljivih posledic, še posebej, ker se ta dejavnost odvija pretežno na okoljsko občutljivih območjih. Če k temu prištejemo še stihijsko izbiro lokacij vrtičkov, ki se zaradi opuščanja kmetovanja izvajajo tudi v neposredni bližini črpališč, ki so namenjena rabi vode za javno oskrbo, je stanje še toliko bolj zaskrbljujoče. Izkušnje iz ljubljanskega prostora kažejo, da vrtičkarska območja sčasoma postajajo nelegalna naselja z neurejenimi higienskimi razmerami, $\mathrm{z}$ neurejenim/nenadzorovanim ravnanjem $\mathrm{z}$ nevarnimi odpadki in kopičenju ostankov fitofarmacevtskih sredstev, nelegalnim odvzemom vode in gradnjo nelegalnih dovoznih poti (Simončič in drugi 2006). 
Slika 2: Območja vrtičkov na Ljubljanskem polju.

Figure 2: Areas of allotment gardens in the area of Ljubljansko Polje.

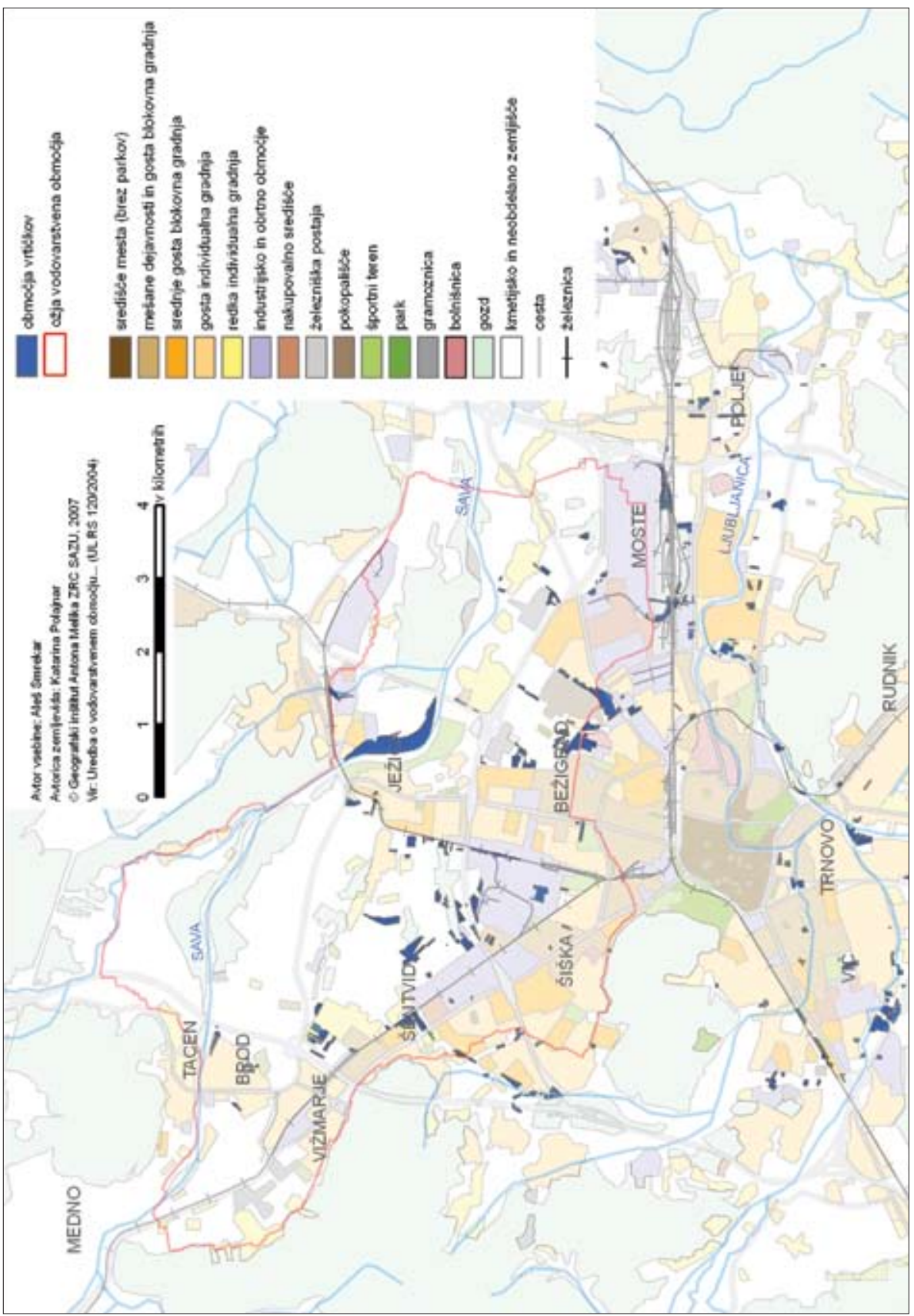


Vrtičkarstvo je zdravstveno in okoljsko sprejemljivo le ob ustreznem znanju o pridelavi vrtnin in odnosu do okolja. Rezultati ankete (Smrekar 2006) so pokazali pri vrtičkarjih izrazito dvojnost v njihovem odnosu do varovanja okolja. Vrtičkarji so na deklarativni ravni okoljsko ozaveščeni, v praktičnem ravnanju pa temu ni tako. Vrtičkarje je potrebno ne samo izobraževati, pač pa tudi ustrezno informirati in ozaveščati o posledicah njihove dejavnosti v okolju in jih čimprej soočiti s potrebnimi spremembami, ukrepi in posegi v njihovo dejavnost. Samo na takšen način bo vrtičkarstvo, ki se je na vodovarstvenih območjih v Ljubljani zaradi neurejenih razmer v preteklih desetletjih že zelo razmahnilo, lažje obvladljivo, predvsem pa strokovno koordinirano.

\subsection{Raba zasebnih vodnjakov}

Informacije o vodnjakih v zasebni lasti so dragocene, saj omogočajo nadzor nad kakovostjo podtalnice na območjih, ki niso stalno vključena $\mathrm{v}$ monitoring podtalnice, kar je lahko pomembno zlasti ob nenadnih nesrečah. Vodnjaki, ki niso registrirani in zato tudi ne nadzorovani, so potencialni točkovni vir onesnaževannja talne vode, saj večinoma niso izdelani v skladu z zahtevami stroke.

Razlikujemo tri glavne tipe vodnih zajetij. Izkopani vodnjaki z večjim premerom in zabiti vodnjaki z majhnim premerom so primerni za oskrbo iz manjših globin, medtem ko so izvrtani vodnjaki prav tako z majhnim premerom primerni za oskrbo iz večjih globin.

Na Ljubljanskem polju smo evidentirali 1228 zasebnih vodnih zajetij (Smrekar in Kladnik 2004). Največ, $49 \%$ je zabitih, le malo manj, to je $46 \%$ je izkopanih, medtem ko je izvrtanih vsega $2 \%$ objektov. Najbolj zgoščena so v Ljubljani pridruženih naseljih vzdolž Save (Brod, Vižmarje, Tacen, Šmartno pod Šmarno goro, Črnuče, Nadgorica, Stožice, Šmartno ob Savi, Hrastje, Sneberje, Polje), v Gameljnah, Šiški in Dravljah.

V preteklosti so bila osredotočena v Ljubljani sami, kjer pa so jih s priključevanjem na vodovodno omrežje pričeli opuščati. Ohranjena so le še ponekod, marsikje bolj zaradi estetskih kot dejanskih potreb. Z množičnim pojavom blokovne gradnje, ki je marsikje izpodrinila starejšo individualno pozidavo, so bili številni objekti uničeni. V strnjeno pozidanem delu mesta jih je moč najti predvsem na območjih, ki so bila strnjeno pozidana do preloma iz 19. v 20. stoletje.

Dobra polovica vodnih zajetij je na vrtu ali dvorišču neposredno ob stanovanjski hiši, malo manj jih je med vrtički, le za vzorec pa je razmeščenih med obdelovalnimi zemljišči, ob križiščih cest ali poti, na vrtovih ali dvoriščih ob javnih objektih ter pod velikimi drevesi sredi nekdanjih vaških naselbin.

V uporabi je tri četrtine vodnih zajetij, druga so opuščena. Opazno je, da je velik delež še uporabljanih zajetij na območjih vrtičkov in v bolj agrarnih okoljih na mestnem obrobju oziroma v njegovem zaledju. Medtem ko je med izkopanimi vodnjaki kar dve tretjini opuščenih, je ta delež med zabitimi in izvrtanimi objekti bistveno manjši.

Raba vode iz zajetij se sčasoma spreminja. Medtem, ko je voda nekoč pomenila glavni vir oskrbe za človeka in živino, se v novejšem času uporablja predvsem za zalivanje in namakanje zemljišč. 
Slika 3: Ohranjenost zasebnih vodnjakov na Ljubljanskem polju.

Figure 3: The preservation of private wells in the area of Ljubljansko Polje.

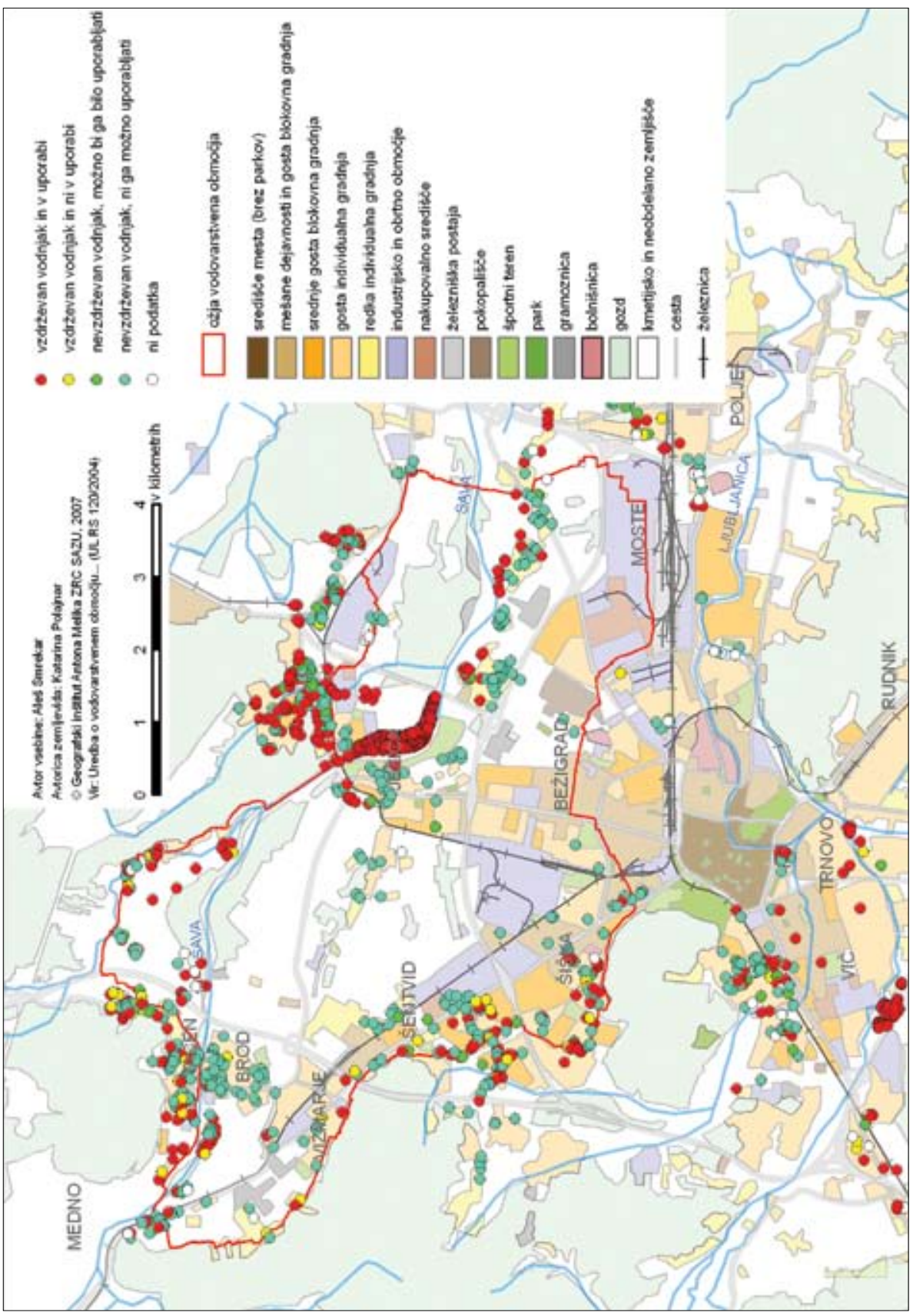


$\mathrm{V}$ posameznih primerih je bilo ugotovljeno neposredno onesnaževanje podtalnice prek izpustov oziroma iztokov odpadne vode v vodnjake. Čeprav se v večino zajetij ne vnaša nobenih tekočin, v izkopane vodnjake nekaterih, ne pav osamljenih primerih odteka kapnica, meteorne vode in celo kanalizacijske odplake. Nevzdrževani vodnjaki so vsekakor potencialne točke onesnaženja podtalnice.

\subsection{Nedovoljeno odlaganje odpadkov}

Na Ljubljanskem polju smo preučili kar 1445 divjih odlagališč odpadkov (Smrekar in drugi 2006). Njihova skupna površina je $120.816 \mathrm{~m}^{2}$, kar pomeni, da je z odpadki prekrito $0,28 \%$ celotnega območja. Gre torej za eno z odpadki najbolj obremenjenih območij v Sloveniji. Skupna prostornina odpadkov znaša $209.422 \mathrm{~m}^{3}$. Povprečno odlagališče meri 83,6 $\mathrm{m}^{2}$ in ima 145,5 $\mathrm{m}^{3}$ odpadnega materiala. Evidentirali smo še 86 gramoznic, 47 obvestilnoopozorilnih tabel in 57 ovir na dovoznih poteh.

Prevladujejo majhna odlagališča, skoraj polovica jih je v velikostnem razredu od 11 do $100 \mathrm{~m}^{2}$. Samo 24 jih presega $1000 \mathrm{~m}^{2}$, vendar ta skupaj zavzemajo 7,3 \% celotne površine odlagališč, pri čemer površino največjega odlagališča ocenjujemo na $6000 \mathrm{~m}^{2}$.

Tudi več kot polovica odlagališč prostorninsko ne presega $10 \mathrm{~m}^{3}$, vendar je na njih odložen le dober odstotek celotne količine ugotovljenih odpadkov. Na drugi strani je 36 odlagališč s prostornino $1000 \mathrm{~m}^{3}$ in več, na katerih je nakopičenih skoraj tri četrtine $(72,5 \%)$ odpadkov. Največje odlagališče vsebuje okrog $42.000 \mathrm{~m}^{3}$ ali skoraj petino ugotovljenih odpadkov.

Manjši del odpadkov je na zemljiščih v zasebni lasti, večina pa je v kategoriji javno dobro oziroma na zemljiščih v lasti pravnih oseb. Vse to razkriva pomanjkljiv nadzor javnega sektorja, četudi so pred nedovoljenim odlaganjem očitno nemočni tudi zasebniki.

Nelegalno odloženi odpadki so le redko homogeni. Večinoma gre za mešanico odpadkov različnega izvora. Tudi na Ljubljanskem polju prevladujejo divja odlagališča z mešanimi odpadki (gradbeni, industrijski, komunalni, odpadki iz primarnega sektorja, jalovina) lokalnega izvora. Njihova lega je pogosto neugodna tako z vidika onesnaževanja podtalnice kot motečega videza, kar vpliva na kakovost bivalnega okolja in rekreacijsko privlačnost pokrajine.

Podrobnejša členitev po vrstah odpadkov je razkrila, da sta dve tretjini odpadkov gradbenega izvora, s petino jim sledijo odpadki primarnega sektorja, medtem ko je komunalnih odpadkov desetina. Druge skupine odpadkov so zanemarljivo zastopane.

Vpliv gradbenih odpadkov na okolje je na splošno zanemarljiv, vendar le, če odpadki ne vsebujejo sestavin, ki bi lahko kemično onesnažile okolje. Nevarne odpadke sestavljajo večinoma odpadna osebna vozila, sodi z neznano vsebino (prazni kovinski sodi so sicer uvrščeni med kosovne odpadke) in embalaže barv, lakov, motornih olj ali agrokemičnih pripravkov. Kot vemo, so komunalni odpadki večinoma trdni, po sestavi heterogeni gospodinjski in njim podobni odpadki, ki nastajajo v proizvodnih in storitvenih dejavnostih, $\mathrm{v}$ bivalnem okolju ter na površinah in objektih $\mathrm{v}$ javni rabi. Zaradi pestre in spremenljive sestave jih je tehnološko težko razstaviti na sestavine.

Rezultati analiz odloženih odpadkov na nekaterih večjih divjih odlagališčih Ljubljanskega polja kažejo, da so heterogeni, vlažni in vsebujejo več organskih snovi, kot je 
Slika 4: Količina in sestava odpadkov divjih odlagališč na Ljubljanskem polju.

Figure 4: The amount and the structure of waste in illegal waste dumps in the area of Ljubljansko polje.

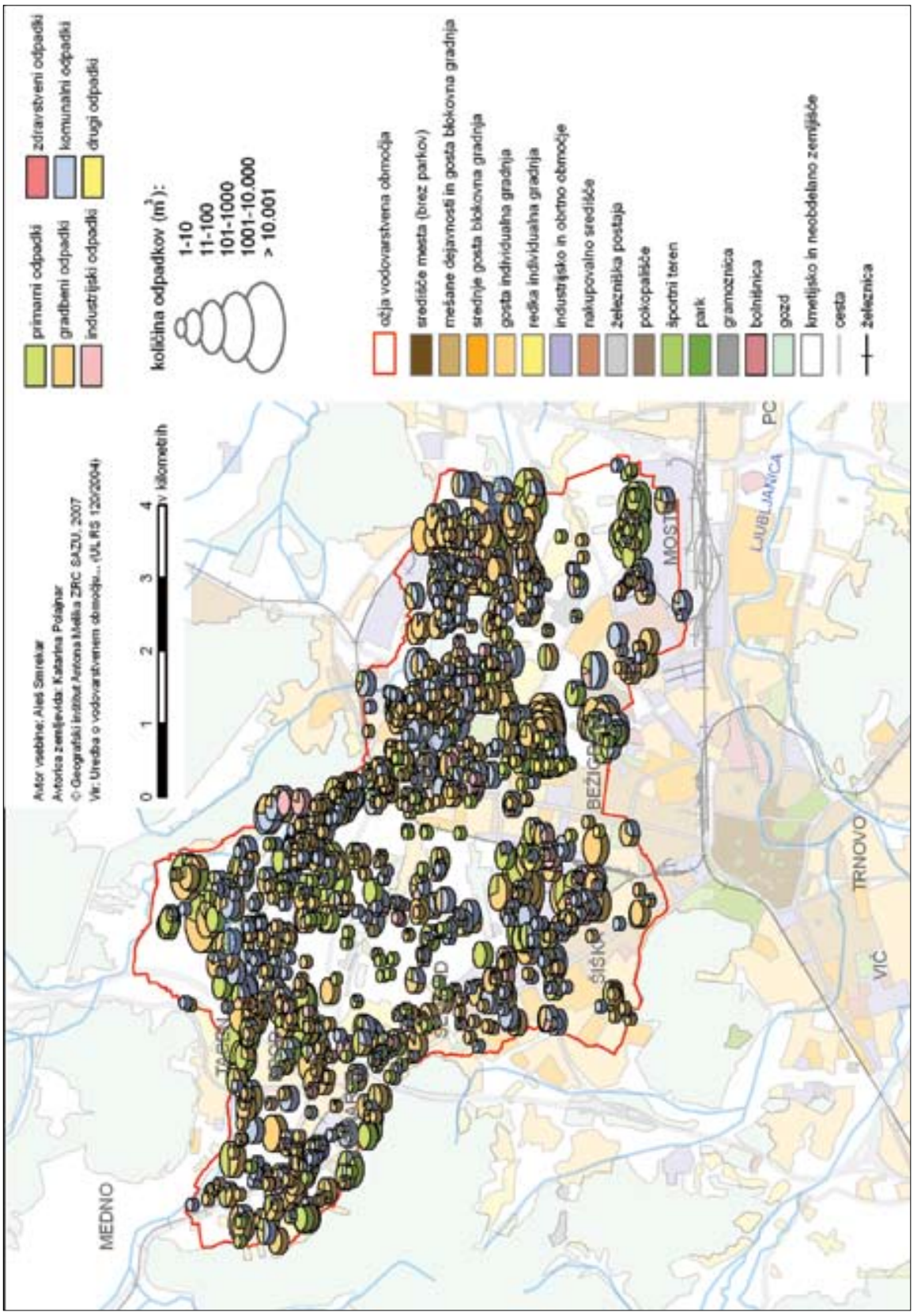


dovoljeno za odlaganje na odlagališča inertnih odpadkov oziroma vnos v tla. Standardni izlužki iz odpadkov so zmerno obremenjeni, vendar nekateri parametri presegajo mejne vrednosti za inertne odpadke oziroma odpadke, ki se lahko vnašajo v tla kot umetno pripravljena zemljina. Po obeh predpisih sta zlasti kritični vsebnosti celokupnih in topnih organskih snovi. Iz tega lahko zaključimo, da je glavni potencialni prispevek odloženih odpadkov k onesnaževanju okolja obremenjevanje z organskimi snovmi biološkega in sinteznega izvora, ki nastajajo pri spontani razgradnji odpadkov v naravnem okolju.

Reševanje problema divjih odlagališč odpadkov bi moralo potekati na dveh ravneh. Na prvi je nujna sanacija obstoječih odlagališč in s tem odstranitev točkovnih in pri večjih ploskovnih virov obremenjevanja podtalnice, na drugi, sočasni, pa je potrebno učinkovito preprečevanje nastajanja novih odlagališč in strogo sankcioniranje morebitnih kršiteljev, pri čemer bi bile nujne tudi akcije za dvig okoljske zavesti.

\subsection{Raba gramoznic}

Najbolj vabljiv dejavnik nenadzorovanega kopičenja velikih količin odpadkov so gramoznice, še zlasti, če se jih po končani eksploataciji ne sanira ustrezno ali pa sploh ne sanira. Velika večina jih je na Ljubljanskem polju, še zlasti če gledamo po količini odloženega materiala. Prodišča južno od Črnuč in Ježice so preprežena z gramoznicami, še zlasti na levem bregu. Večje koncentracije so tudi še ob desnem bregu Save vzhodno od Roj in ob levem bregu zahodno od Spodnjih Gameljn. Gre za ogromne tujke v prostoru, njihova površina se giblje med 25 in 65.000 kvadratnimi metri, prostornina pa znaša od 50 do 130.000 kubičnih metrov. Njihova globina je tudi 6 m, izjemoma celo več kot 10 m (Smrekar in drugi 2006).

Štiri legalne gramoznice večjega obsega so v Stanežičah, na območju Dovježa jugozahodno od krožišča v Tomačevem in v Obrijah. Vse so v fazi sanacije. Te gramoznice k sreči niso v večji meri zasipavali z odpadki, saj so jih po letu 1924, ko se je začel njihov organiziran odvoz, odvažali zlasti v južne dele Ljubljane (Orožen Adamič in Pleskovič 1975) in tako z odpadki niso sistematično ogrožali podtalnice Ljubljnskega polja.

Zaskrbljujoče je, da je 126 divjih odlagališčih v gramoznicah, kjer je odloženih skoraj dve tretjini vseh popisanih odpadkov s skoraj polovico skupne površine odlagališč. $\mathrm{Na}$ Ljubljanskem polju smo evidentirali 87 gramoznic, med njimi pa je le 15 praznih (Smrekar in drugi 2006).

Obdobja trajanja - življenja določene gramoznice so zelo različna. Pri nekaterih se je celoten morfološki ciklus od izkopa do zasutja ali zaraščanja obrnil v petih letih. Jugovzhodno od vodarne Jarški prod je nazoren primer nesaniranega ekološkega bremena iz preteklosti. Prve manjše gramoznice so se na tem območju pojavile leta 1959, uporabljali so jih do leta 1975. Njihova povprečna površina je bila do $5000 \mathrm{~m}^{2}$. V sedemdesetih letih so se posamezne gramoznice združile v obsežno območje izkoriščanja na površini 75.000 $\mathrm{m}^{2}$. Gramoznica je bila aktivna do leta 1985, ko se je začela zaraščati s travo. Popisovalci so konec leta 2004 na območju te gramoznice popisali največja odlagališča odpadkov, velika do $5000 \mathrm{~m}^{2}$. Gramoznico so v osemdesetih letih 20. stoletja začeli zasipavati, pozneje pa so osrednji del zasadili z drevesi (iglavci). Znotraj gramoznice se je do danes ohranilo omrežje makadamskih poti, po katerih se je v obdobju izkopavanja odvažalo velike količine gramoza, 
Slika 5: Dinamika spreminjanja površin gramoznic na Jarškem produ.

Figure 5: The dynamics of the transformation of the gravel surface in the area of Jarški prod.

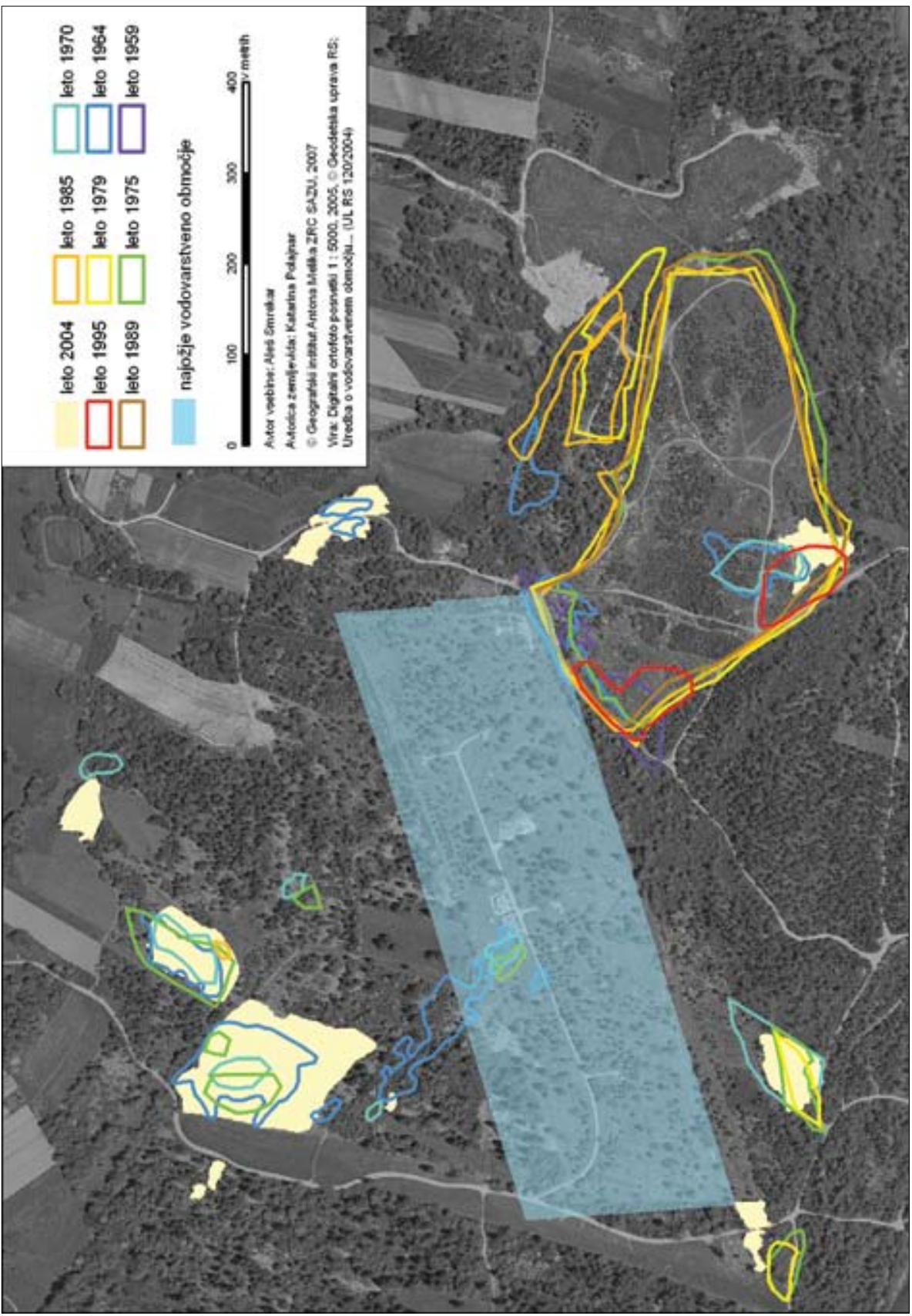


pozneje pa so bile ključne za dovažanje odpadkov (Smrekar in drugi 2005). Dostopnost je eden ključnih dejavnikov za nastanek odlagališč odpadkov v gramoznicah. Čeprav so na nekaterih dostopnih poteh postavljene ovire, jih je praviloma mogoče obiti in tako do gramoznic neovirano pripeljati odpadno gradivo. Na območju gramoznice so odloženi različni odpadki neznane sestave in so nenehna grožnja podtalnici zaradi možnosti izpiranja snovi iz odlagališč odpadkov v podtalnico. Na površju prevladujejo gradbeni odpadki, ki so povečini nenevarni za podtalnico. Toda material je heterogen in ponekod neznane sestave, zato je kljub analizi še vedno možno onesnaženje podtalnice.

\section{SKLEP}

V občinskem Prostorskem planu (2002) je zapisano: “... Prioritetna naloga Mestne občine Ljubljana je varna oskrba s pitno vodo, zato je treba prostorski razvoj prilagajati potrebam ohranitve virov pitne vode ...".

Funkcija črpanja vode, ki je na prvem mestu in njej morajo biti podrejene vse druge dejavnosti, bi bila lahko nadgrajena $\mathrm{z}$ rekreacijsko in vzgojno dejavnostjo. Nujno bi bilo potrebno uravnovesiti koriščenje vseh naravnih virov, ki jih območje nudi. Pitna voda ima seveda prvenstveno vlogo in zato, da bi jo zaščitili, bi morali popolnoma prekiniti tradicijo izkoriščanja proda in nedovoljenega odlaganja odpadkov.

Za uspešno udejanjanje ciljev trajnostnega razvoja neurbaniziranega dela Ljubljane so potrebni informiranje, izobraževanje in ozaveščanje.

Prizadevanja brez podpore in primerne okoljske ozaveščenosti lokalnega prebivalstva zagotovo ne bodo dosegla cilja, to je urejene in zdrave domače pokrajine. Ljudje morajo spremeniti življenjski slog, tako da bodo prostorske vrednote postale njegov sestavni del. Neproblematično okolje mnogim očitno še ne pomeni vrednote. Na preučenem območju je za zdaj takšnih manj kot četrtina (Smrekar 2006). Obveščanje, izobraževanje in osveščanje posameznikov in družbenih skupin je zagotovilo za oblikovanje zrelega in odgovornega odnosa do prostora, v katerem živimo (Urbanc, Fridl 2007). Slednje mora postati vrednota, ki bo zasedala visoko mesto na vrednostni letvici ljudi. Za običajnega človeka je vrednota pojem o temeljnih kategorijah želenega, dobrega, pozitivnega (Urbanc 2006), ali kot pravi Slovar slovenskega knjižnega jezika (1995), da je namreč vrednota tisto, čemur kdo priznava veliko načelno vrednost in mu zato daje prednost.

Vendar to še zdaleč ni dovolj. Doslej tudi politične volje in posledično sredstev za reševanje neugodnega stanja ni bilo dovolj. V zadnjem času je mestna oblast očitno spoznala nujnost ukrepanja. Prav na podlagi okoljskih študij o vrtičkarstvu (Simončič in drugi 2006), zasebnih vodnjakih (Smrekar in Kladnik 2004) in odlagališčih odpadkov ter gramoznicah (Smrekar in drugi 2005; Smrekar in drugi 2006), kjer so najbolj aktivno sodelovali prav geografi iz ti. Radinjeve šole, so bili v letu 2007 storjeni prvi konkretni koraki na poti k reševanju okoljskih problemov v teh predelih Ljubljane.

Vrtičkarstvo se je na vodovarstvenih območjih v Ljubljani zaradi neurejenih razmer v preteklih desetletjih že razmahnilo v obsegu, ki je težko obvladljiv. Ukinitev vrtičkarstva in s tem tudi zasebnih vodnjakov na nekaterih obstoječih lokacijah v Ljubljani, zlasti v bližini 
vodarn, je kljub odporu prizadetih ljudi, nujno. Ker je nadzor nad delovanjem vrtičkarjev, uporabo gnojil in zaščitnih sredstev na vrtičkih pravzaprav nemogoč in ker je njihova uporaba pogosto nestrokovna, je povsem na mestu prizadevanje, da na ožjem vodovarstvenem območju vrtičkov sploh ne bi bilo. V okviru študije (Simončič in drugi 2006), ki poteka, bo potrebno določiti ustreznejše lokacije, ki so za takšno dejavnost primerne in predstavljajo manjšo nevarnost za podtalnico ter okolje $\mathrm{v}$ širšem smislu.

Tudi sanacija divjega odlaganja odpadkov je nujna. Študija o divjih odlagališčih odpadkov (Smrekar in drugi 2006) je pokazala, da je najbolj obremenjen Jarški prod. In Mestna uprava pripravlja prav za to območje sanacijski projekt, ki mu bo sledila pilotna izvedba sanacije. Na podlagi teh rezultatov se bodo celostno lotili reševanja te problematike v vsej Ljubljani. Ena od možnih dolgoročnih rešitev bi lahko bila, da bi območja, katerih osnovna funkcija bo ostala črpanje pitne vode, dodali nove vsebine.Današnje degradirana območja bi morali s sanacijami spremeniti v zelene površine, ki bi mestnemu prebivalstvu omogočale sprostitev, rekreacijo ali celo izobraževanje, kar bi lahko zagotovila na primer ureditev učne poti.

Razni formalni ukrepi bodo lahko postali učinkoviti šele takrat, ko bodo Ljubljančani $\mathrm{v}$ tem prostoru prepoznali novo vrednoto in bo zato $\mathrm{v}$ njihovi zavesti dobil posebno mesto kot javni prostor. Ljudje naj bi ga dojemali kot »sobo na prostem«, kot se je izrazila Ward Thompsonova (Ward Thompson 2002), kjer bi se sproščali in uživali ob različnih aktivnostih. Seveda pa morajo biti vse te dejavnosti usklajene $\mathrm{z}$ najpomembnejšo funkcijo, to je črpanjem kakovostne vode za mestno oskrbo.

Območje, ki je v preteklosti omogočalo okolju prijazne dejavnosti, bi lahko zelo kmalu postalo okoljsko breme. Zaenkrat analize podtalnice še kažejo na njeno ustreznost (Bračič in Jamnik 2005), vendar je območje zaradi nenadzorovanih posegov že v preteklosti, ki se še vedno dogajajo, tudi prikrita grožnja, saj ne vemo natančno, kje in kakšna vse so stara bremena. Za celostno in dolgoročno uspešno rešitev problema zgolj sanacija prostora ne bo zadoščala, ampak bo potrebno ponovno vzpostaviti kulturne in socialne vrednote območja ter ga umestiti $v$ trajen vrednostni sistem meščanov.

\section{Viri in literatura}

Bračič Železnik, B., Jamnik B. 2005: Javna oskrba s pitno vodo. V: Podtalnica Ljubljanskega polja. Geografija Slovenije 10. Ljubljana.

Breg, M., Urbanc, M. 2005. Gramoznice in dileme (ne)trajnostnega razvoja degradirane obrečne pokrajine. IB 34-4. Ljubljana.

Galluser, W. A., Schenker, A., 1992. Die Augen am Oberrhein - Les zones alluviales du Rhin supérior. Basel, Boston, Berlin.

Kladnik, D. 2002: Pomen in perspektive zasebnega kmetijstva znotraj strnjeno pozidanih delov Ljubljane. Inštitut za geografijo. Ljubljana.

Orožen Adamič, M., Pleskovič, B. 1975: Problemi okolja in odlaganja trdih odpadkov v Ljubljani. Geografski vestnik 47. Ljubljana.

Podobnik, J., 2007: Za večjo teritorialno kohezijo in trajnostna mesta. Okolje in prostor, 128, str. 1-2. Ljubljana. Ministrstvo za okolje in prostor. 
Plut, D., 2003. Geografske teoretične in metodološke zasnove proučevanja degradacije okolja : študijsko gradivo za Varstvo geografskega okolja. 246 str. Ljubljana: Filozofska fakulteta Univerze v Ljubljani.

Prostorski plan Mestne občine Ljubljana, Prostorska zasnova. Ljubljana, 2002.

Rejec Brancelj, I. 2001: Kmetijsko obremenjevanje okolja v Sloveniji. Ljubljana.

Richling A., 1999: Landscape classification of the areas transformed by man. Nature and Culture in Landscape Ecology, CZ-IALE, Prague.

Simončič, A., Sušin, J., B., Jamnik, B., Bračič Železnik, B., Smrekar, A., Breg, M., Kladnik, D. 2006: Vrtičkarstvo v Mestni občini Ljubljana kot vir onesnaževal v tleh, pridelani hrani in podzemni vodi. Ljubljana.

Simoneti, M., Bevk, J., Pintar, M., Zupan, M., Gajšek, P., Golobič, M., Pleško, R., Bevk, M. 1997: Usmeritve in pogoji za nadaljnji razvoj vrtičkarstva v Ljubljani. Poročilo o razvojno-raziskovalni nalogi. Ljubljanski urbanistični zavod. Ljubljana.

Slovar slovenskega knjižnega jezika. Ljubljana, 1995.

Smrekar, A., 2004. Reduced Permeation of Percipitation Water into Groundwater on Ljubljansko polje-Zmanjšano prenikanje padavinske vode v podtalnico na Ljubljanskem polju. Acta geographica Slovenica - Geografski zbornik, 44-2, str. 35-47. Geografski inštitut Antona Melika ZRC SAZU. Ljubljana.

Smrekar, A., Breg, M., Fridl, J., Kladnik, D., Urbanc, M., Bračič-Železnik, B., Jamnik, B., Grilc, V., Husić, M., Kušar, S. 2005: Izdelava katastra in predloga prednostne sanacije odlagališč odpadkov vodozbirnega območja črpališča Jarški prod. Geografski inštitut Antona Melika Znanstvenoraziskovalnega centra Slovenske akademije znanosti in umetnosti. Ljubljana.

Smrekar, A., Breg, M., Slavec, P., Bračič-Železnik, B., Jamnik, B., Grilc, V., Husić, M. 2006: Odlagališčaodpadkovnavodovarstvenemobmočju,pomembnemzaoskrboMestneobčine Ljubljana s pitno vodo. Geografski inštitut Antona Melika Znanstvenoraziskovalnega centra Slovenske akademije znanosti in umetnosti. Ljubljana.

Smrekar, A. 2006: Zavest ljudi o rabi pitne vode. Geografija Slovenije 12. Ljubljana.

Smrekar,A., Kladnik, D. 2004: Popis vodnjakov in vrtinv zasebni lastina območju vodnih virov Mestne občine Ljubljana. Geografski inštitut Antona Melika Znanstvenoraziskovalnega centra Slovenske akademije znanosti in umetnosti. Ljubljana.

Urbanc, M., 2006: Report of the R.A.V.E. Space educational seminar for teachers in Portorož. Geografski inštitut Antona Melika Znanstvenoraziskovalnega centra Slovenske akademije znanosti in umetnosti. Ljubljana.

Urbanc, M., Breg, M., 2005. Gravel plains in urban areas: gravel pits as an element of degraded landscapes. Acta Geographica Slovenica 45-2. Ljubljana.

Urbanc, M., Fridl, J. 2007: Izobraževanje mladih kot pomemben dejavnik trajnostnega razvoja: na primeru projekta R.A.V.E. Space. Ozaveščanje o prostoru kot pomemben dejavnik izobraževanja za trajnostni razvoj; primer projekta R. A. V. E. Space. V: Veliki razvojni projekti in skladni regionalni razvoj. Regionalni razvoj 1. Ljubljana.

Ward Thompson, C., 2002: Urban open space in the 21st century. Landscape and Urban Planning 60, 59-72Berque, A., Conan, M., Donadieu, P., Lassus, B., Roger, A. 1994: Cinq propositions pour une théorie du paysage. Champ Vallon, Pariz. 


\section{COINCIDENTAL (NON)-DEVELOPMENT OF THE NON- URBANIZED PART OF THE CITY IN THE CASE OF LJUBLJANA}

\section{Summary}

Urbanization causes changes within cities and their surrounding areas and deviates from the concepts of sustainable development. In narrow water-protection zones in the area of Ljubljansko Polje there are areas without any contents, if we don't take into account water pumping, which attracts some inadequate forms of land usage.

Non-urbanized areas, which were after the building not used in a profitable manner and are in a long-term view foreseen for building, and some individual agricultural areas, on which the interest for agriculture has dropped, and in some cases also for recreational areas, which await some concrete regulation interventions for public recreational offer, are put under a lot of pressure from specific groups of the public. These groups often see these areas, which are mainly in the water-protection zones, as a source of carrying out some unsuitable activities, i.e. allotment gardening, individual illegal scooping of water from the groundwater, gravel removal and illegal waste dumping.

Allotment gardening is one of the most coincidental beneficiaries of valuable city space. It is located beside some business areas, on the embankments of railway tracks, on the embankments of rivers and creeks, in unused building areas, between arable lands and meadows, beside forests and block of flats. From year to year the number of small, forced locations has risen, for which it is apparent, that they are a result of big needs of users for maintaining gardens. This fact also shows the lack of any kind of control of the owner or manager of the area, regarding its use or appearance. Only some individual areas, which were planned for allotment gardening, are adequately maintained and have been used for allotment gardening for a long period of time. Without doubt we can differentiate two extreme groups within allotment gardeners. The one, which because of its lack of knowledge, exaggerates with the use of fertilizers and means for plant-protection, and the second group, which due to the environmental awareness, uses only the methods of biological production. Nonprofessional use of pharmaceuticals derived from plants and the use of fertilizers represents a danger for water sources and safe public supply of drinking water as it is often in conflict with an organized use of space and the urbanistic plan of the city.

We registered 1228 private water sources in the area of Ljubljansko Polje. 75 percent of them are currently in use, others are abandoned. It is clear, that the biggest share of sources still used is located in the vicinities of gardens and in more arable areas. In the past water was the main source of supply for humans and livestock, but nowadays it is mostly used for watering and irrigation of the land.

The biggest and the hardest problem to control are without doubt illegal waste dumps, 1445 of which are registered and were studied in the area of Ljubljansko Polje. Their common surface is $120.816 \mathrm{~m}^{2}$, which means that $0,28 \%$ of the whole area is covered with waste. The common volume of waste is $209.422 \mathrm{~m}^{3}$. The predominant are illegal waste dumps with mixed waste (building, industrial, communal, waste from the primary sector, tailings) of local origin. Their location is often inconvenient from the perspective of polluting the 
groundwater as well as because of their improper appearance, which influences the quality of living environment and the recreational attractiveness of the region.

The most attractive factor of uncontrollable accumulation of big amounts of waste are gravel pits, especially if they weren't adequately rehabilitated or weren't rehabilitated at all after they were exploitated. The banks of the river Sava are covered with gravel pits. These are seen as enormous foreign objects within the environment, their common surface being between 25 and $65000 \mathrm{~m}^{2}$ and the volume being between 50 and $130.000 \mathrm{~m}^{3}$. Their depth is 6 , in some cases even more than $10 \mathrm{~m}$. A worrying fact is that 126 illegal waste dumps are located in the gravel pits, where almost $66 \%$ of all registered waste is dumped.

The function of pumping water, which is the dominant one and to which all other activities have to be subordinated, would possibly be upgraded with a recreational and educational activity. It would be necessary to balance the usage of natural sources, which are part of the environment. The area would have to get a new role, with which it would become a sort of a natural park in the urban surroundings.

For a successful fulfilment of the goal of sustainable development regarding the nonurbanized area of Ljubljana the support and adequate environmental awareness of the population are needed. Only a quarter of the population of this area is environmentally aware on a satisfactory level. Up till now there was no real political willingness and adequate funds secured for the solution of the inconvenient situation. In the year 2007 first concrete steps on the way of solving environmental problems in this parts of Ljubljana, were made. 